\title{
Temporal patterns of blood flow and nitric oxide synthase expression affect macrophage accumulation and proliferation during collateral growth
}

\author{
Journal of Angiogenesis Research 2:18 I DOI: 10.1186/2040-2384-2-18 I C Li et al.; licensee Publiverse Online \\ S.R.L. 2010 \\ Received: 19 Jan 2010 | Accepted: 16 Jan 2010 | Published: 16 Jan 2010 \\ Sager Hendrik B ${ }^{@}$, Middendorff Ralf, Rauche Kim, Weil Joachim, Lieb Wolfgang, Schunkert Heribert, \\ Ito Wulf D \\ ${ }^{+}$Contributed equally ${ }^{@}$ Corresponding author
}

\begin{abstract}
Background

The involvement of collateral blood flow/fluid shear stress, nitric oxide (NO), and macrophages during collateral growth (arteriogenesis) is established, but their interplay remains paradoxical.

\section{Methods}

In order to further elucidate the "fluid shear stress/NO/macrophage" paradox, we investigated the time course of collateral blood flow (using a Doppler flow probe) and NOS expression (immunohistochemistry, Western blot) in growing rat collateral vessels after femoral artery occlusion and their impact on macrophage recruitment and collateral proliferation (immunohistochemistry, angiographies).
\end{abstract}

\section{Results}

(values are given as mean \pm standard error of mean) Early after occlusion, collateral blood flow was significantly reduced (pre- $90.0 \pm 4.5$ vs. post-occlusion $62.5 \pm 5.9 \mu \mathrm{l} / \mathrm{min} ; p<0.01$ ), and local inducible NOS (iNOS) and endothelial NOS (eNOS) expression were down-regulated (expression in \% of non-occluded: eNOS $49.4 \pm 11.8 \%$ and iNOS $54.5 \pm 7.9 \%$ vs. non-occluded at $12 \mathrm{~h}$ after occlusion; $p<0.03$ ). An artificial rise (induced by a peripheral vasodilatation) of the initially decreased collateral blood flow back to pre-occlusion levels reduced collateral macrophage recruitment (macrophages per collateral section: post- $42.5 \pm 4.4$ vs. artificial pre-occlusion $27.8 \pm 2.0 ; p<0.05$ ) and diminished collateral proliferation (proliferative index: post- $0.54 \pm 0.02$ vs. artificial pre-occlusion $0.19 \pm 0.04 ; p<0.001$ ) significantly $72 \mathrm{~h}$ after femoral artery occlusion.

\section{Conclusions}

We propose the following resolution of the "fluid shear stress/NO/macrophage" paradox: Collateral blood flow and NOS expression are initially reduced during arteriogenesis allowing macrophages to accumulate and therewith enhancing collateral proliferation. After homing of macrophages ( $24 \mathrm{~h}$ after occlusion), collateral blood flow and NOS expression recover in order to join the effects of macrophages for restoring blood flow.

\section{Background}

Investigations conducted during the last decade have demonstrated that growth of collateral arteries involves pre-existing arteriolar anastomoses [1]. This phenomenon is restricted to certain vessels within a region and occurs largely outside ischemic territories [2]. These characteristics are distinguished from angiogenesis, the sprouting of capillaries within ischemic territories, and vasculogenesis, that is, the in situ growth of vascular structures from immature precursor cells [ $3]$. The term arteriogenesis has therefore been established for the remodeling process of pre-existing arteriolar shunts into large conductance vessels. It is now widely accepted that flow dependent forces (e.g. fluid shear stress, defined as the viscous drag of flowing blood on the endothelial lining) and macrophage accumulation play a pivotal role during that process [4]. Below, we describe these major components of arteriogenesis. 


\section{Shear stress}

As compared to circumferential wall stress, fluid shear stress (FSS) is a rather weak force and mostly acts on endothelial cells. After arterial occlusion, a steep pressure gradient develops between proximal and distal areas of conductance vessels. According to Ohm's law, the increase in proximal to distal pressure gap could only be explained by an increase of flow velocities in pre-existing shunts if resistances and diameters remained the same. Elevated collateral blood flow directly results in elevated collateral fluid shear stress [ 4, 5]. Artificial elevations of collateral flow using arterio-venous shunts lead to vascular remodeling processes very similar to collateral growth [6].

\section{Monocytes/Macrophages}

Early macrophage recruitment during maximal proliferation is another hallmark of collateral artery growth and was first described in dog heart collateral vessels [7]. Subsequent investigations in the rabbit and rat hind limb revealed that macrophage recruitment occurred very early during collateral growth and paralleled maximal proliferation of endothelial and smooth muscle cells [ 1,8$]$. Several studies demonstrated that enhancement of macrophage recruitment and survival accelerated collateral growth. In this context, the chemokine MCP-1 (monocyte chemotactic protein-1), is a strong chemotactic factor for monocytes/macrophages, and a potent stimulator of arteriogenesis [9]. Animals deficient in the MCP-1 receptor CCR2 (C-C chemokine receptor 2) demonstrated reduced arteriogenic potential [ 10], underscoring the importance of MCP-1 in arteriogenesis. Macrophages secrete the majority of growth factors during maximal proliferation $[9,11]$.

\section{Nitric oxide}

Even if recent studies provide strong evidence that arteriogenesis requires nitric oxide (NO) [ 12], its specific role during that process remains elusive.

On one hand, it was demonstrated that increased blood flow leads to higher nitric oxide (NO) production by the endothelium via stimulation of endothelial nitric oxide synthase (eNOS) expression [ 13] and activation [ 14]. Indeed, transcripts for eNOS and inducible nitric oxide synthase (iNOS) were found to be up-regulated on both transcriptional

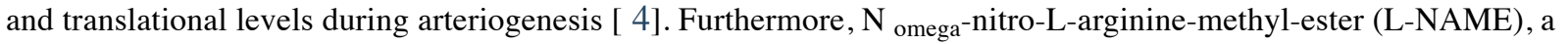
potent NOS inhibitor, markedly inhibited the effects of increased FSS [ 15] on arteriogenesis. In addition, NO enhances proliferation and migration of endothelial cells in vitro [16] and transgenic mice lacking the eNOS showed reduced angiogenic and arteriogenic capabilities [ 17, 18].

On the other hand, NO reduces MCP-1 expression in macrophages and endothelial cells [ 19, 20] and leads to decreased expressions of cell adhesion molecules such as CD11, CD18, VCAM-1 (vascular cell adhesion molecule-1), and ICAM-1 (intercellular adhesion molecule-1) [ 21,22], counteracting an adhesion of monocytes to the activated endothelial lining. Furthermore, macrophage accumulation occurs under low rather than elevated flow [23] challenging the hypothesis that increased FFS promotes arteriogenesis.

\section{The shear stress/nitric oxide/macrophage paradox}

Thus, the effect of increased flow (fluid shear stress) on NO expression and monocyte recruitment in the context of arteriogenesis appears paradoxical: On the one hand, elevated blood flow leads to increased local levels of NO, which has been shown to promote collateral growth in several studies [ 12,24]. At the same time, increased flow and NO levels impedes monocyte homing and macrophage accumulation, likewise critical steps during collateral growth. For example, macrophages and monocytes accumulate during collateral growth, suggesting an important role during collateral proliferation.

In the present study we provide a possible explanation for this paradox and hypothesize that a very early phase of collateral growth is characterized by low collateral blood flow conditions, allowing macrophages to adhere, and thus, enhance collateral proliferation.

\section{Methods}

\section{Animal model}

A rat model of peripheral artery insufficiency with unilateral femoral artery occlusion was used as described previously [ 1]. Experiments were conducted on 103 male Spraque Dawley rats weighting 350 - $450 \mathrm{~g}$. All surgical procedures were performed under general anesthesia induced by $\mathrm{CO}_{2} / \mathrm{O}_{2}$ inhalation and continued by intra-peritoneal injections of ketamin (100 mg/kg bodyweight; Atarost GmbH \& Co, Twistringen, Germany) and xylazin 2\% (5 mg/kg bodyweight; Bayer Vital GmbH, Leverkusen, Germany). Either MCP-1 (450 ng/ml in PBS) or PBS (phosphate-buffered saline as vehicle) was administered directly into the collateral circulation via osmotic mini pumps $(2 \mathrm{ml}$ model, $10 \mu \mathrm{l} / \mathrm{h}$ for $7 \mathrm{~d}$, Alzet, Palo Alto, USA). The non-specific NO-synthase inhibitor L-NAME (Sigma-Aldrich, St. Louis, USA) was given through the drinking water, which was available fresh daily beginning $2 \mathrm{~d}$ before surgical procedures and continued throughout the whole study (7 d). Each rat received 65-70 mg L-NAME per kg and per day. Rats of the non-L-NAME groups received ordinary tap drinking water. The investigation conforms with the Guide for the Care and Use of Laboratory Animals published by the US National Institutes of Health (NIH Publication No. 85-23, revised 1996). The study was performed according to section 8 of the German Law for the Protection of Animals and was approved by the local ethic committee (TV No. 5402, Behörde für Umwelt und Gesundheit der Freien Hansestadt Hamburg, 18.09.2002). 


\section{Experiments on the later phase ( $7 \mathrm{~d}$ after initiating of collateral growth, Figure 1C)}

We functionally investigated the interdependency of macrophage recruitment and NO availability (experimental set-up from Figure 1C) during collateral growth via a combination of enhanced macrophage recruitment (MCP-1 infusion) and NO antagonism (L-NAME administration). Fifty-nine rats were included in these analyses (31 rats for the macrophage accumulation and proliferation analyses and 28 rats for the angiographic experiments). Either MCP-1 or PBS was administered directly into the collateral circulation via osmotic mini pumps. The non-specific NO-synthase inhibitor LNAME was given through the drinking water, which was available fresh daily beginning $2 \mathrm{~d}$ before surgical procedures. Determination of macrophage accumulation and proliferative index was performed as described above; post-mortem angiographies are described below.

\section{Results}

\section{Experiments on the early phase $(0-72 \mathrm{~h}$ after initiation of collateral growth, Figure $1 \mathrm{~A}+\mathrm{B})$}

To examine the level of NO producing enzymes in collateral vessel walls, quantitative Western blot analyses of NOS expression were performed at different time points after initiation of arteriogenesis (experimental set-up from Figure 1A). As shown in Figure 3 , the expression of the NOS was initially (12 h post-occlusion) down-regulated compared to expression levels in non-femoral occluded pre-existing collaterals ( $p<0.03$ vs. non-occluded). $24 \mathrm{~h}$ post-occlusion, the expression of both eNOS and iNOS then exceeded the corresponding levels in non-occluded animals by almost 50\% ( $p$ $<0.03$ vs. non-occluded). $72 \mathrm{~h}$ after occlusion, eNOS and iNOS expression did not differ between occluded and nonoccluded animals.

Figure 3

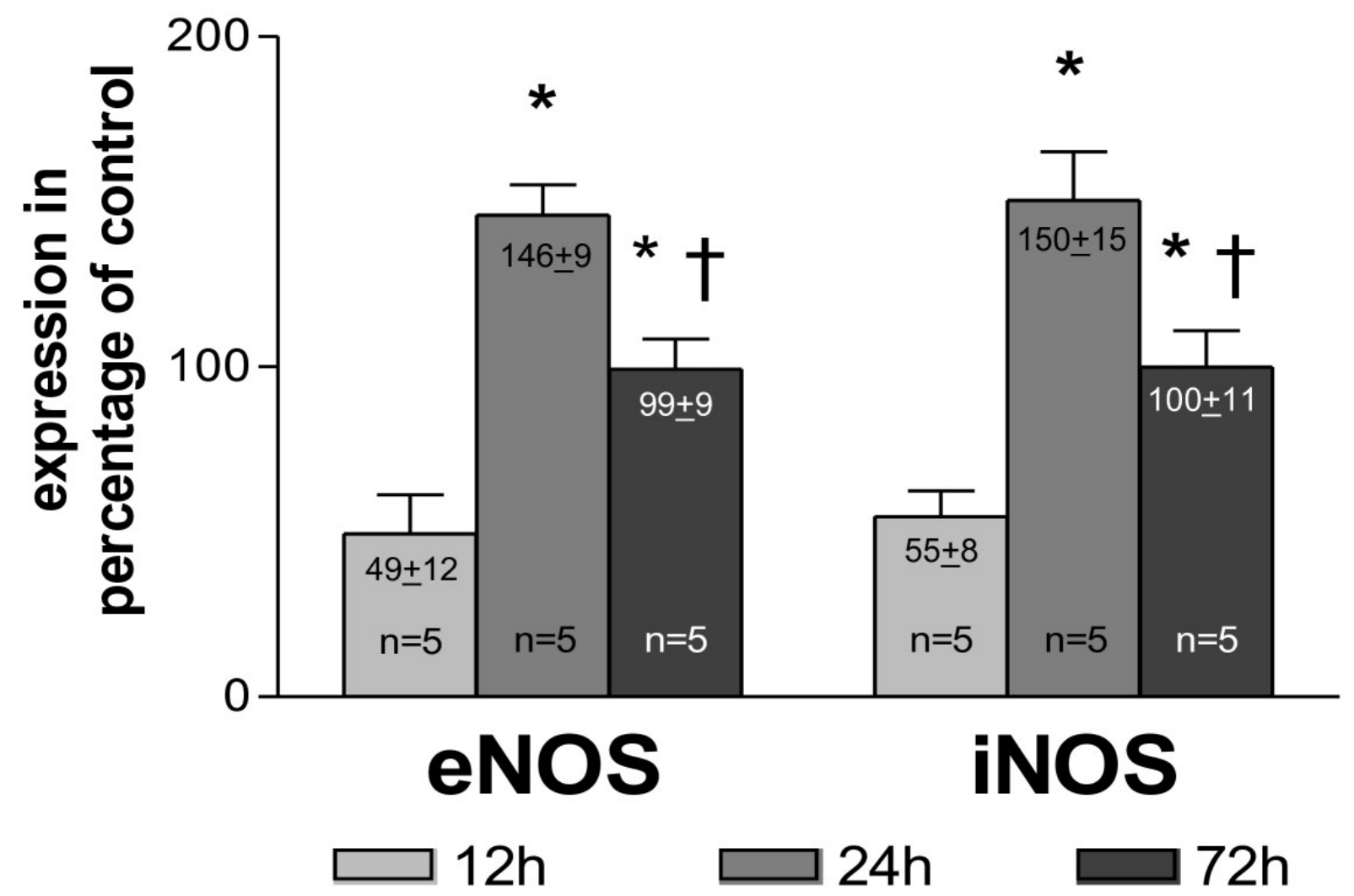

Quantification of collateral NOS expression. as percentage of control vessels (main collateral arteries from nonoccluded hind limbs) at different time points after femoral artery occlusion, $* p<0.03$ vs. $12 \mathrm{~h}, \dagger p<0.03$ vs. $24 \mathrm{~h}$.

Blood flow in the main collateral vessel was $90.0 \pm 4.5 \mu \mathrm{l} / \mathrm{min}$ at resting conditions (Figure 4 ). After acute femoral artery occlusion, blood flow significantly decreased by almost one-third. An acute peripheral, intra-arterial application of 500 $\mu \mathrm{g}$ GTN into the distal stump of the occluded femoral artery (experimental set-up from Figure 2 ) restored collateral blood flow to pre-occlusion levels after $3 \mathrm{~min}$.

Figure 4 


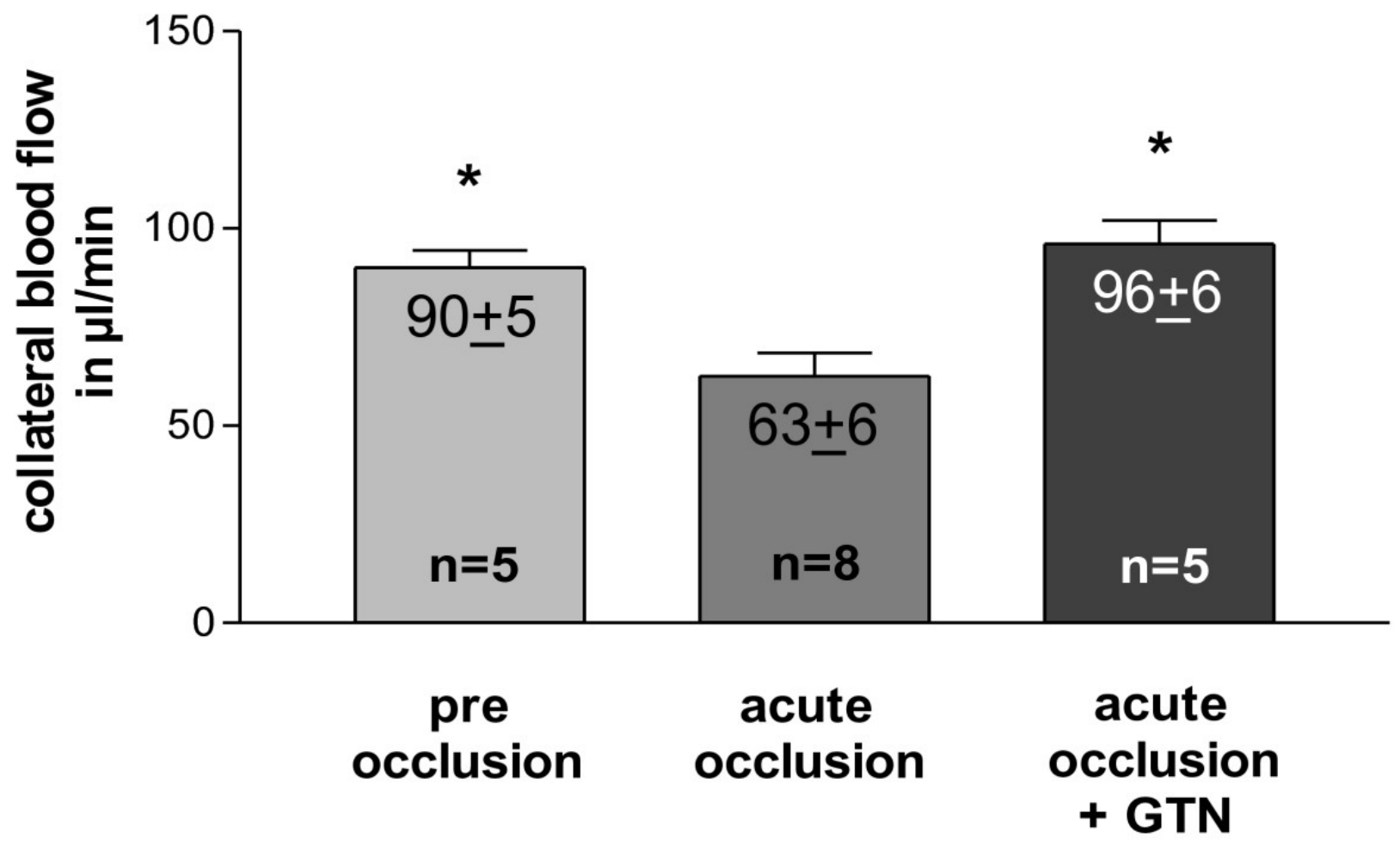

Quantification of blood flow. in main collateral artery (rudimental ischiadic artery) at pre and post femoral artery occlusion levels (with or without an acute peripheral intra-arterial administration of $500 \mu \mathrm{g}$ nitroglycerin [GTN]); * $p$ $<0.01$ vs. acute occlusion.

In order to assess the functional impact of the initial collateral flow depression on macrophage accumulation and collateral proliferation, initial blood flow levels were artificially elevated via infusion of GTN (experimental set-up from Figure 1B ). Chronic GTN infusion (over $72 \mathrm{~h}$ ) significantly reduced the number of pericollateral ED2 positive macrophages by more than one-third (Figure $5 \mathrm{~A}+\mathrm{B}$ and Figure 6A).

Figure 5 

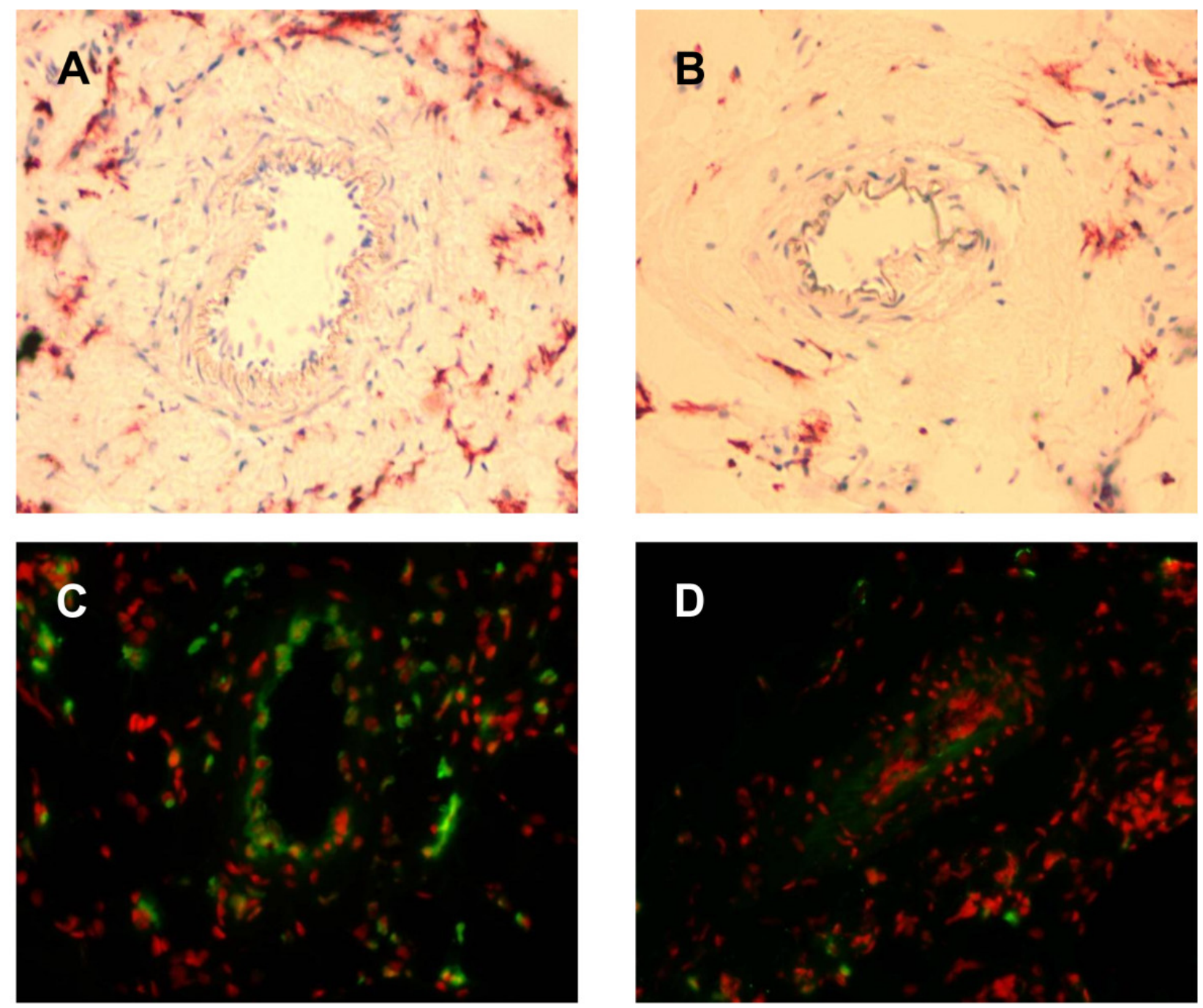

$\mathrm{A}+\mathrm{B}$, Immunohistochemical detection of resident macrophages. in the absence (panel A; occlusion) and presence (panel B; occlusion + GTN) of continuous, peripheral GTN infusion $(10 \mu \mathrm{g} / \mathrm{h}$ over $72 \mathrm{~h}) 72 \mathrm{~h}$ after femoral artery occlusion, 20x magnification. C $+\mathrm{D}$, Fluorescence immunohistochemical detection of BrdU-incorporated nuclei(green) in the absence (panel C; occlusion) and presence (panel D; occlusion + GTN) of continuous, peripheral GTN infusion (10 $\mu \mathrm{g} / \mathrm{h}$ over $72 \mathrm{~h}) 72 \mathrm{~h}$ after femoral artery occlusion; 20x magnification, 7-Amino-actinomycin D nuclear stain (red fluorescence).

Figure 6 
A

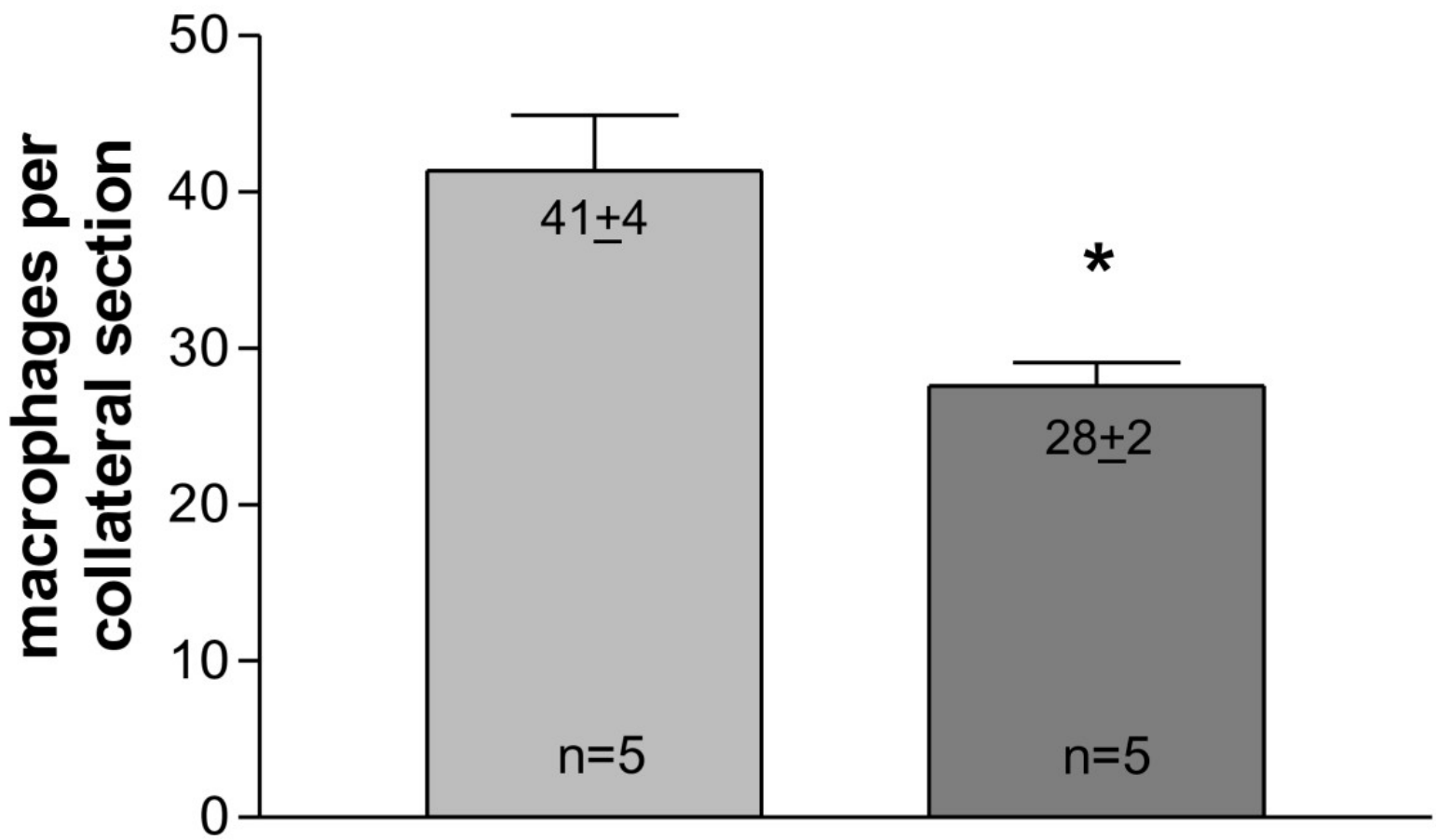

B

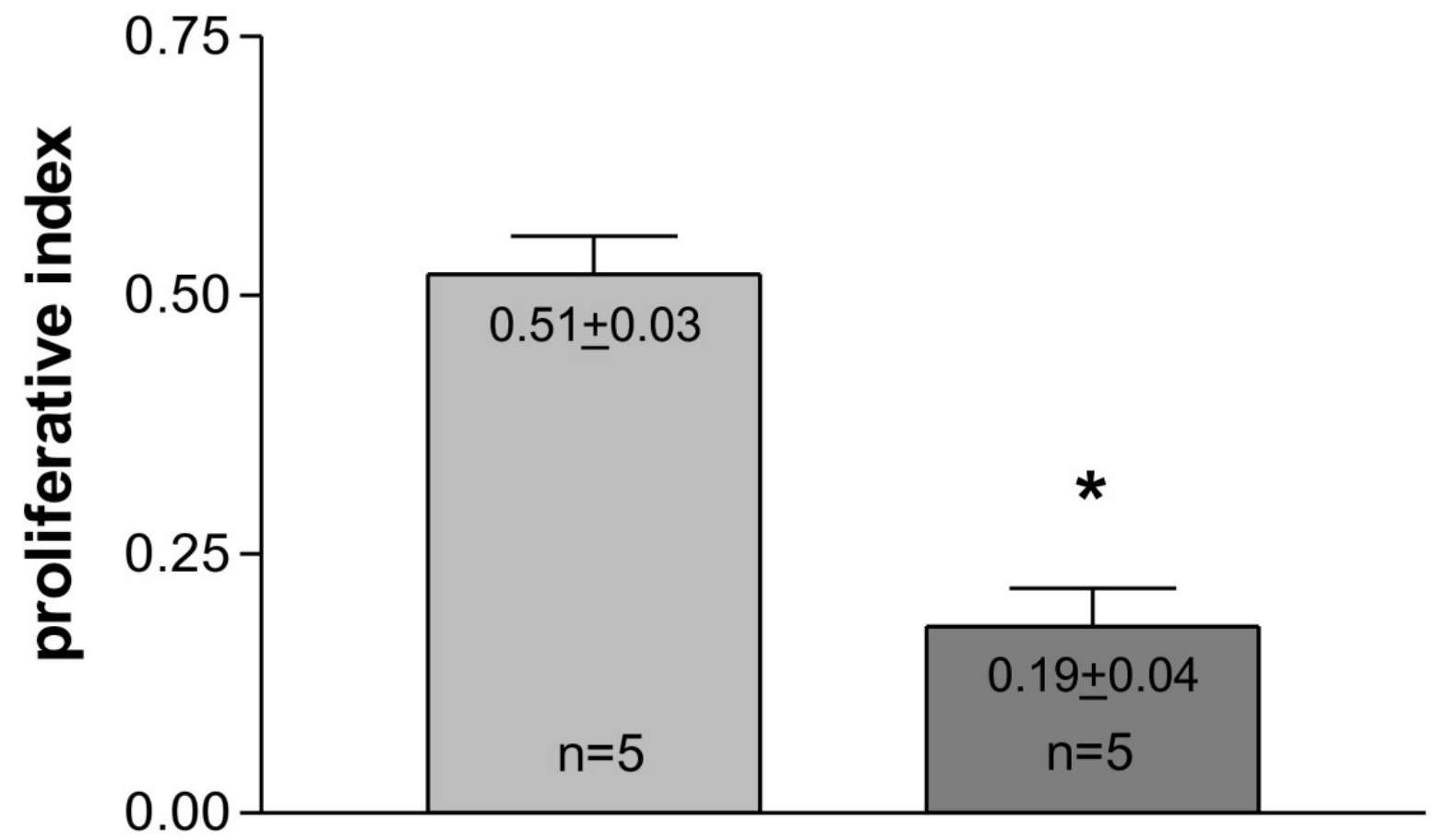

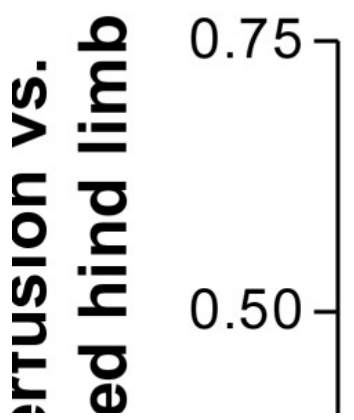




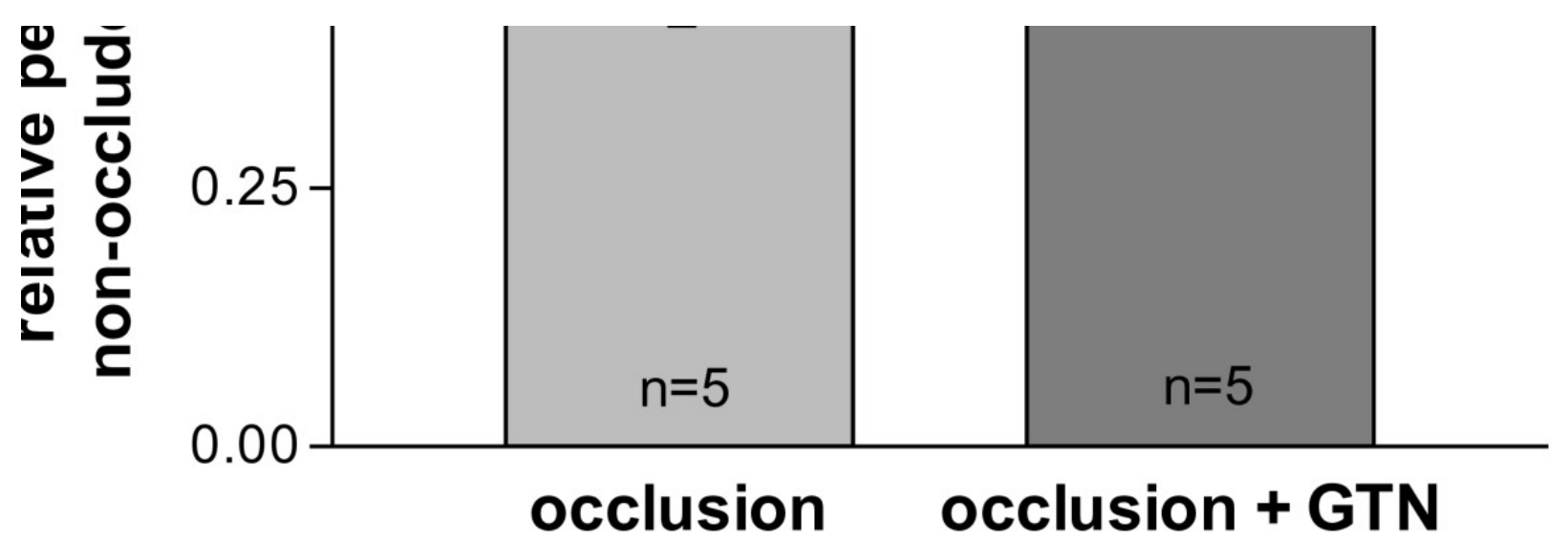

A, Quantification of resident macrophages. per collateral section in the absence (occlusion) and presence (occlusion + GTN) of continuous, peripheral GTN infusion $(10 \mu \mathrm{g} / \mathrm{h}$ over $72 \mathrm{~h}) 72 \mathrm{~h}$ after femoral artery occlusion, ${ }^{*} p<0.05$ vs. occlusion. B, Quantification of proliferationin the absence (occlusion) and presence (occlusion + GTN) of continuous, peripheral GTN infusion $(10 \mu \mathrm{g} / \mathrm{h}$ over $72 \mathrm{~h}) 72 \mathrm{~h}$ after femoral artery occlusion, ${ }^{*} p<0.001$ vs. occlusion. C, Quantification of collateral-dependent tissue perfusionin the absence (occlusion) and presence (occlusion + GTN) of continuous, peripheral GTN infusion $(10 \mu \mathrm{g} / \mathrm{h}$ over $72 \mathrm{~h}$ ). Ischemic limb perfusion $72 \mathrm{~h}$ after femoral artery occlusion was expressed as a ratio of fluorescent microsphere counts in ischemic soleus muscle and related to non-femoral oc cluded leg (set as 1).

This reduced number of macrophages surrounding collateral vessels (72 h after occlusion with ongoing GTN supply) was accompanied by a reduction of collateral proliferation (Figure 5C $+\mathrm{D}$ and Figure $6 \mathrm{~B}$ ). Continuous GTN application decreased proliferative index (PI) by almost two-thirds.

To assess collateral-dependent tissue perfusion, fluorescent microsphere analyses were performed. Relative perfusion of ischemic vs. non-ischemic limbs (soleus muscle) $72 \mathrm{~h}$ after femoral artery occlusion remained equal in chronic GTN- or non-GTN-treated rats (Figure 6C).

\section{Experiments on the later phase (7 d after initiating of collateral growth, Figure 1C)}

Chronic MCP-1 treatment led to a higher macrophage accumulation around main collateral vessels as compared to the vehicle (phosphate-buffered saline, PBS, treated) group (Figure 7A). Likewise, chronic L-NAME treatment enhanced the number of pericollateral macrophages in the PBS as well as in the MCP-1 group. Consistently, MCP-1 significantly increased proliferation in collateral vessels (Figure 7B ). However, NO antagonism (L-NAME) had no effect on collateral proliferation neither in PBS nor in MCP-1 treated animals. Chronic oral L-NAME treatment led to decreased scores of angiographically visible collateral vessels $7 \mathrm{~d}$ after femoral artery occlusion (Figure 7C), whereas chronic MCP-1 administration significantly enhanced collateral growth reflected in a larger amount of vessels in the collateral network. This positive effect of MCP-1 could not be antagonized by L-NAME treatment.

\section{Figure 7}


A

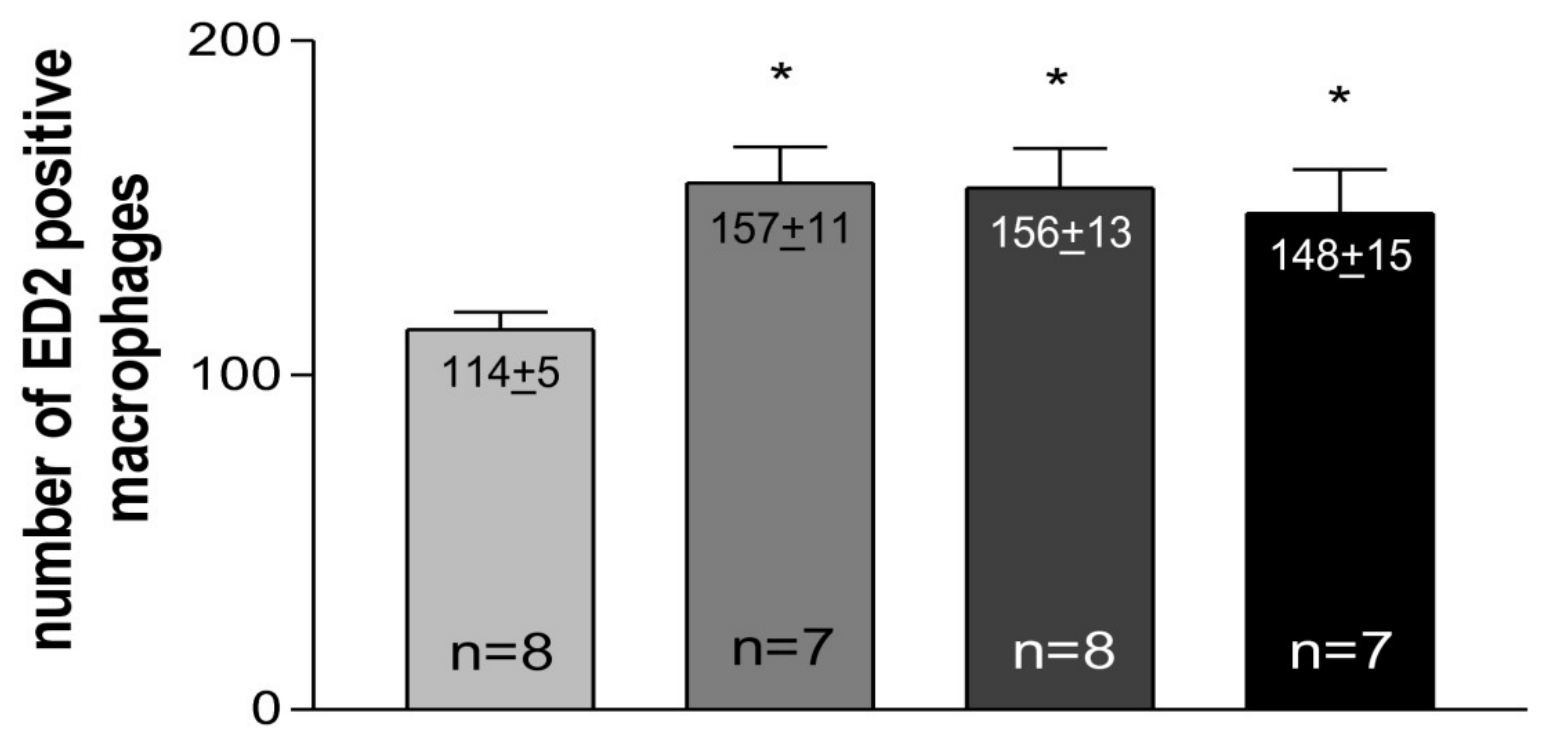

B
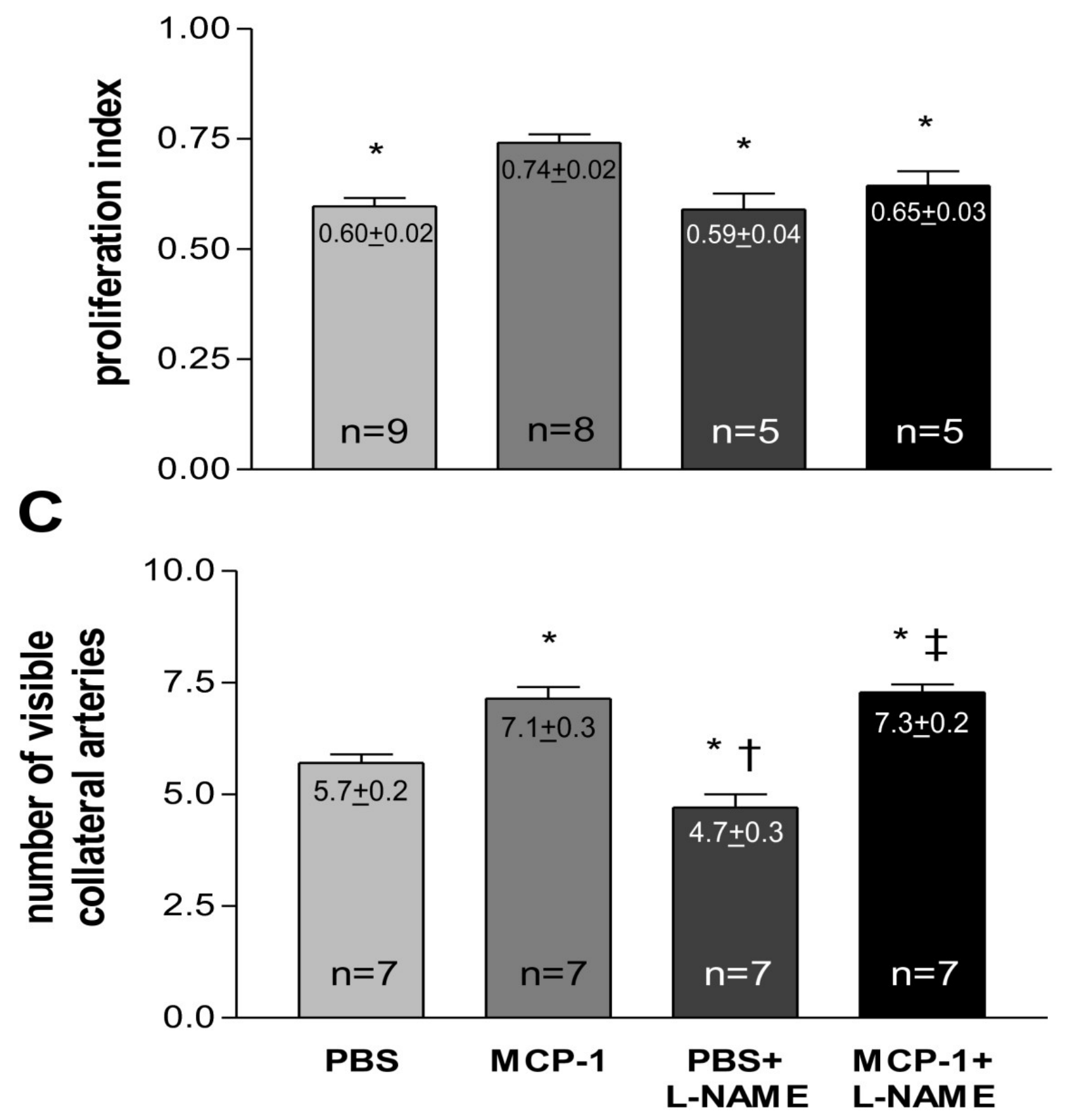
A, Quantification of resident macrophage. (mature, ED2 positive) accumulation in vehicle (PBS), MCP-1, vehicle $(\mathrm{PBS})+\mathrm{L}-\mathrm{NAME}$ and MCP-1 + L-NAME treated animals $7 \mathrm{~d}$ after femoral artery occlusion, macrophage score per collateral section, ${ }^{*} p<0.05$ vs. PBS. B, Quantification of collateral proliferationin vehicle (PBS), MCP-1, vehicle $(\mathrm{PBS})+\mathrm{L}-\mathrm{NAME}$ and MCP-1 + L-NAME treated animals $7 \mathrm{~d}$ after femoral artery occlusion, proliferative index, $* p$ $<0.05$ vs. MCP-1. C, Quantification of angiographically visible collateral vesselsin vehicle (PBS), MCP-1, vehicle (PBS) + L-NAME and MCP-1 + L-NAME treated animals $7 \mathrm{~d}$ after femoral artery occlusion, number of visible collaterals, $* p<0.03$ vs. PBS, $\dagger p<0.001$ vs. MCP- $1, \ddagger p<0.001$ vs. PBS + L-NAME.

\section{Discussion}

The cardinal paradox of the arteriogenesis hypothesis on the initiation of collateral growth was that monocyte accumulation, a crucial step in this process, occurred primarily under low rather than high blood flow conditions [ 22 , 23]. However, collateral blood flow/FSS was thought to be elevated during the entire build-up of collateral vessels. Thus far, experimental data on the regulation of blood flow in collateral vessels was missing. In this study, we present a possible solution to this "FSS/NO/macrophage" paradox during collateral growth.

Our study demonstrates that collateral growth is a complex process characterised by a sequence of distinct steps, beginning with an early phase between 0 and $12 \mathrm{~h}$ after initiation. This phase is characterized by low collateral flow conditions (Figure 4) and a rather low local NO concentration (Figure 3 ), allowing macrophages to adhere to the endothelium and to migrate through the collateral vessel wall. A second phase between 12 and $24 \mathrm{~h}$ after initiation is characterized by elevated collateral flow and increased NO availability (Figure 3 ). Collateral proliferation might be set off during this phase. Once migrated, macrophages need a certain degree of NO concentration and elevated flow during this stage of arteriogenesis to differentiate and proliferate locally (Figure 7B ).

Our analyses demonstrated that the expression of NOS was significantly down-regulated $12 \mathrm{~h}$ post-occlusion (Figure 3 ), correlating with initially increased monocyte/macrophage recruitment [ 22, 23], but rose significantly beyond expression levels in non-occluded control animals within 24 to $72 \mathrm{~h}$ post-occlusion. Based upon these initial findings, we hypothesize that collateral flow and local NO production were initially decreased in collateral arteries, allowing the recruitment of circulating cells, which can differentiate locally during the following days. To assess this hypothesis, we measured blood flow directly in the stem region of the main collateral artery in the rat hind limb (rudimental ischiadic artery) via a transonic flow probe. In agreement with our hypothesis, flow velocities decreased acutely after femoral artery occlusion. Interestingly, a previous study published by our group provided a potential explanation for this observation [ 2]. In a rabbit model we observed a marked increase in peripheral resistance directly after femoral artery occlusion. This increase in peripheral resistance could explain why the flow remains rather low, despite an increase of the pressure gradient across the collateral circulation.

An acute GTN (a strong vasodilator reducing peripheral resistance) infusion blunted this initial decrease of flow in the collateral vessel (Figure 4). An ongoing infusion of GTN during the first $3 \mathrm{~d}$ after femoral artery occlusion (time period of maximal macrophage accumulation) decreased macrophage accumulation and collateral proliferation (Figure 6A + B ). These findings indeed support the notion that the initial decrease of flow in collateral vessels is important for collateral macrophage accumulation and, at the same time, for collateral proliferation.

During the later phase of collateral growth, local activation of initially immigrated cells might either be triggered by paracrine mechanisms of the FSS activated endothelium or via tensile forces. These hypotheses are supported by the observation that most proliferation of cells occurs in the direct vicinity of collateral vessels [ 1]. Because the number of pericollateral macrophages and collateral proliferation was decreased in the "occlusion + GTN" (Figure 6A + B) as compared to "occlusion without GTN" group, we also expected to find a reduced collateral-dependant perfusion. However, finding no substantial difference in tissue perfusion between both groups might be explained by the following: Firstly, the collateral-dependant peripheral tissue perfusion (soleus muscle) is, in fact, reduced due to less pericollateral macrophages, and thus, less proliferation of the upstream lying collaterals, but the effect is abolished by a GTN-induced peripheral vasodilatation. Actually, the fact that collateral-dependant perfusion is not reduced could be an indirect hint that GTN was effective for $72 \mathrm{~h}$ and that nitrate tolerance was less likely to have occurred. Secondly, the effect of an enhanced tissue perfusion in the "occlusion" group (due to enhanced collateral proliferation) only occurs on physical activity (when maximal collateral flow is demanded) and not, as in our case, under resting conditions.

After our initial experiments, revealing reduced collateral blood flow and NO availability $12 \mathrm{~h}$ after femoral artery occlusion, but increased flow and NO availability thereafter, we administered L-NAME in order to inhibit this early collateral NO peak (occurring $24 \mathrm{~h}$ after occlusion). The late phase (chronic) experiments were conducted to investigate the mid- or long-term effects of the now modulated early phase. In order to do so, we assessed the impact of chronic NOS inhibition (oral L-NAME administration) and macrophage chemotaxis (intracollateral MCP-1 administration) on macrophage accumulation and collateral proliferation as well as on angiographically visible collaterals.

MCP-1 alone led to a late (7 d after femoral artery occlusion; Figure 7A) enhanced number of pericollateral macrophages and therewith to an increased collateral proliferation (Figure 7B) and a larger amount of visible collaterals (Figure 7C). These results are in line with previous publications [ 1,8,9]. L-NAME alone as well as in combination with MCP-1 led to a late enhanced macrophage accumulation ( $7 \mathrm{~d}$ after occlusion; Figure $7 \mathrm{~A}$ ) possibly by further reducing already decreased early NO bioavailability (12 h after occlusion; Figure 3 ). 
Surprisingly, the L-NAME group did not show an increased collateral proliferation, despite the increased number of macrophages as compared to the PBS group. It appears that if L-NAME inhibits the collateral NO peak (occurring $24 \mathrm{~h}$ after occlusion; Figure 3 ) macrophages are not able to enhance collateral proliferation (not even in the presence of MCP1). One could speculate that NO is essential for the differentiation and local proliferation of already migrated macrophages. The fact that the total number of collaterals was reduced (Figure 7C) in the L-NAME group is most likely due to a vasoconstrictive effect of L-NAME and in line with previous reports by Mees at al. showing that the transient decrease in collateral blood flow in eNOS knockout animals is mainly due to the inability to vasodilate [ 24].

Furthermore, it appears that MCP-1 somehow abolished the vasoconstrictive effect of L-NAME (reflected in an increased number of collaterals; Figure 7C). This finding is rather unexpected because a direct vasodilatory effect of MCP-1 has not, to our knowledge, been described yet.

Our study highlights that collateral growth is a multi-phase process with different distinct stages. Elevated CBF/FSS and increased NO production appear to be restricted to later phases of collateral growth. Thus, studies investigating the impact of an artificially elevated FSS on collateral growth, for instance via construction of an arterio-venous shunt, are capable of elucidating certain mechanisms of collateral growth but will possibly miss others. In this context, it is noteworthy that in the first study investigating the effect of shunting on collateral growth, shunts were created $7 \mathrm{~d}$ after femoral artery occlusion [ 6]. According to our findings, the short period of low CBF/FSS and macrophage recruitment had long passed at this time point. Furthermore, several studies showed that the peak of macrophage recruitment and proliferation occurred during the first week after femoral artery occlusion and was followed by a prolonged phase of vascular remodeling $[1,2,28]$. Thus, the arterio-venous shunt in the study of Pipp et al. probably enhanced and prolonged the remodeling phase of collateral growth. At this time point, neither macrophage recruitment nor proliferation is very prominent anymore $[2,8,28]$. The later extensive remodeling phase of collateral growth rather appears to be driven by migratory processes and possible further stimulation of progenitor cells that are mainly vascular resident at this time [ 25,29]. While a recent study failed to show an effect of the small GTPase Rac2 on collateral growth [ 30], Eitenmuller et al. were able to demonstrate that the Rho-GTPase pathway was activated during arterio-venous shunting of collateral vessels at the time of femoral artery occlusion [ 15]. This pathway plays an important role in migratory processes. L-NAME abolished the positive effect of arterio-venous shunting on collateral conductance. Unfortunately, neither macrophage accumulation nor collateral proliferation was investigated in this study. Taken together, the findings of Eitenmuller et al. and Pipp et al., in conjunction with our data, suggest that arterio-venous shunting enhances collateral conductance via prolongation and augmentation of the remodeling phase of collateral growth that occurs after the initial phase characterized by vascular proliferation and macrophage accumulation [ 1,28]. As the results of our study do not contradict investigations showing a dramatically increasing remodeling process of collateral vessels after construction of an arterio-venous shunt, they also do not contradict findings demonstrating the importance of the NO system in stem cell mobilization during vascular growth, because our study focuses on local kinetics in collateral vessels and not on the bone marrow niche that may be subject to quite different kinetics at the same time [31]. Finally, the question arises whether our model of an acute occlusion of the femoral artery resembles the pathophysiological situation encountered in human patients. In the human heart, this certainly only pertains to the situation of an acute myocardial infarction. In this setting, the kinetics of collateral growth are indeed similar to the ones seen in our model [ 32].

\section{Limitations of study}

The major limitation of our study is that we provide data only on CBF and not on FSS (the main stimulus of collateral growth). Collateral shear stress can be calculated by using the following equation assuming Newtonian fluid dynamics, if the collateral blood flow $(Q)$, the blood viscosity $(\eta)$, and the internal radius of the collateral vessel $(R)$ are provided. F

$\mathrm{S} \mathrm{S}=4 \times \eta \times \mathrm{Q} \pi \times \mathrm{R} 33_{\pi \times R^{3}}^{F S S=\frac{4 \times \eta \times Q}{}}$

The equation demonstrates that increased blood flow will only directly result in increased FSS if blood viscosity and the radius/diameter of the vessel remained the same.

Our experimental set-up (with extended surgery) only allowed us to measure temporal changes in collateral blood flow velocities but not changes in collateral diameter in the same animal at the same time. Obtaining the collateral diameter is rather challenging as the main collateral vessel is rather small (according to our data, around 150 to $200 \mu \mathrm{m}$ [ 1]) and it also must be obtained very accurately because, according to the Hagen-Poiseuille law, a $10 \%$ change in radius alters FSS by approximately $30 \%$ and a $20 \%$ change equates to $70 \%$. Although collateral diameters can be obtained (e.g. with the use of MR angiographies), it was not feasible in our study after all the applied surgical techniques. The level of NOS expression can give a rather indirect hint to how shear stress changes during arteriogenesis since NOS expression is FSS dependent.

It furthermore might seem rather puzzling that we measured NOS expression on one hand (Figure 1A) and administered an NO donor on the other hand (Figure 1B). It is important to note that, as shown in Figure 1, NOS expression measurements and administration of NO donors (GTN) were performed in independent experiments; specifically, NOS expression therefore was never measured in the presence of an NO donor (GTN). GTN was administered in order to reduce peripheral resistance and to open up the ischemic microcirculation, but certainly has several limitations. However, alternative substances such as selective resistance vessel vasodilators did not seem to be suitable in our experimental setting. For example, adenosine has a short life span and had not, to our knowledge, been used in osmotic pumps. Even if the GTN was given peripheral to the collateral network (Figure 2) in a small dose, a low degree of reflux into the collateral network cannot be excluded. NO generated from GTN could also directly affect collateral monocyte/macrophage adherence and cell proliferation after entering the systemic circulation and the collateral network. Nitrate tolerance normally develops after $72 \mathrm{~h}$ of continuous high-dose exposure, while we used low-dose administration up to a maximum of $72 \mathrm{~h}$. 
Because we focused on macrophages only, we could have missed effects of other immune and inflammatory cells on collateral proliferation. There is, for example, strong evidence that CD4-positive lymphocytes provide an arteriogenic effect by recruiting macrophages to the site of active collateral growth [ 33].

\section{Conclusions}

We present, for the first time, direct evidence of natural blood flow kinetics in collateral vessels after femoral artery occlusion. According to our data, CBF as well as NOS expression is initially reduced during arteriogenesis, allowing macrophages to accumulate and therewith enhancing collateral proliferation. These results help clarifying important questions concerning the arteriogenesis hypothesis, in particular, the interplay of CBF/FSS, NO, and macrophage recruitment.

\section{Declarations}

\section{Acknowledgements}

This study was supported by the German Research Foundation (Deutsche Forschungsgemeinschaft (DFG): IT 13/2-1, IT 13/2-2, IT 13/2-3 and SFB 547, Projekt C13), the Bundesministerium für Bildung und Forschung (BMBF: $01 G N 0127$ and 01GN0521) and the German National Genome Research Network (NGFN-Plus: FK 01GS0831).

\section{Authors' original submitted files for images}

Below are the links to the authors' original submitted files for images.

Authors' original file for figure 1

Authors' original file for figure 2

Authors' original file for figure 3

Authors' original file for figure 4

Authors' original file for figure 5

Authors' original file for figure 6

Authors' original file for figure 7

\section{Competing interests}

The authors declare that they have no competing interests.

\section{Authors' contributions}

HBS, RM, KR, and WDI carried out the experimental work and drafted the manuscript. WDI, JW, WL, and HS conceived the study, participated in its design and coordination, and helped to draft the manuscript. All authors read and approved the final manuscript.

\section{References}

1. Herzog S, Sager H, Khmelevski E, Deylig A, Ito W. Collateral arteries grow from preexisting anastomoses in the rat hindlimb. Am J Physiol Heart Circ Physiol. 2002;283:H2012-H2020.

$\underline{\text { View Article } \text { Google Scholar }}$

2. Ito WD, Arras M, Scholz D, Winkler B, Htun p, Schaper W. Angiogenesis but not collateral growth is associated with ischemia after femoral artery occlusion. Am J Physiol. 1997;273:H1255-H1265.

View Article Google Scholar

3. Carmeliet P. Mechanisms of angiogenesis and arteriogenesis. Nature Medicine. 2000;6:389-395.

View Article Google Scholar

4. Schaper W Collateral circulation: past and present Basic Res Cardiol 200910415212755790 10.1007/s00395-008-0760-X

5. Heil M, Schaper W. Influence of mechanical, cellular, and molecular factors on collateral artery growth (arteriogenesis). Circ Res. 2004;95:449-58. 
6. Pipp F, Boehm S, Cai WJ, Adili F, Ziegler B, Karanovic G, Ritter R, Balzer J, Scheler C, Schaper W, SchmitzRixen T. Elevated fluid shear stress enhances postocclusive collateral artery growth and gene expression in the pig hind limb. Arterioscler Thromb Vasc Biol. 2004;24:1664-8.

$\underline{\text { View Article }} \underline{\text { Google Scholar }}$

7. Schaper J, Koenig R, Franz D, Schaper W. The endothelial surface of growing coronary collateral arteries. Intimal margination and diapedesis of monocytes A combined SEM and TEM study. Virchows Arch A (Pathol Anat). 1976;370:193-205.

View Article Google Scholar

8. Arras M Ito WD Scholz D Winkler B Schaper J Schaper W Monocyte activation in angiogenesis and collateral growth in the rabbit hindlimb J Clin Invest 19981014050508538 10.1172/JCI119877

9. Ito WD, Arras M, Winkler B, Scholz D, Schaper J, Schaper W. Monocyte chemotactic protein-1 increases collateral and peripheral conductance after femoral artery occlusion. Circ Res. 1997;80:829-837.

$\underline{\text { View Article } \text { Google Scholar }}$

10. Heil M, Ziegelhoeffer T, Wagner S, Fernandez B, Helisch A, Martin S, Tribulova S, Kuziel WA, Bachmann G, Schaper W. Collateral artery growth (arteriogenesis) after experimental arterial occlusion is impaired in mice lacking CC-chemokine receptor-2. Circ Res. 2004;94:671-7.

View Article Google Scholar

11. Schaper W, Piek JJ, Munoz-Chapuli R, Wolf C, Ito W. Collateral Circulation of the Heart. Angiogenesis and Cardiovascular Disease. 1999;:159-198.

View Article Google Scholar

12. Troidl K, Tribulova S, Cai WJ, Ruding I, Apfelbeck H, Schierling W, Troidl C, Schmitz-Rixen T, Schaper W. Effects of endogenous nitric oxide and of DETA NONOate in arteriogenesis. J Cardiovasc Pharmacol. 2010;55:153-60.

View Article Google Scholar

13. Li Y, Zheng J, Bird IM, Magness RR. Effects of pulsatile shear stress on nitric oxide production and endothelial cell nitric oxide synthase expression by ovine fetoplacental artery endothelial cells. Biol Reprod. 2003;69:1053-9.

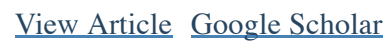

14. Busse R, Fleming I, Schini VB. Nitric oxide formation in the vascular wall: regulation and functional implications. Curr Top Microbiol Immunol. 1995;196:7-18.

View Article Google Scholar

15. Eitenmuller I, Volger O, Kluge A, Troidl K, Barancik M, Cai WJ, Heil M, Pipp F, Fischer S, Horrevoets AJ, Schmitz-Rixen T, Schaper W. The range of adaptation by collateral vessels after femoral artery occlusion. Circ Res. 2006;99:656-62.

View Article Google Scholar

16. Dimmeler S, Dernbach E, Zeiher AM. Phosphorylation of the endothelial nitric oxide synthase at ser-1177 is required for VEGF-induced endothelial cell migration. FEBS Lett. 2000;477:258-62.

View Article Google Scholar

17. Lee PC, Salyapongse AN, Bragdon GA, Shears LL, Watkins SC, Edington HD, Billiar TR. Impaired wound healing and angiogenesis in eNOS-deficient mice. Am J Physiol. 1999;277:H1600-8.

$\underline{\text { View Article }}$ Google Scholar

18. Cui X Chopp M Zacharek A Zhang C Roberts C Chen J Role of endothelial nitric oxide synthetase in arteriogenesis after stroke in mice Neuroscience 20091592744502743134 10.1016/j.neuroscience.2008.12.055

19. Zeiher AM, Fisslthaler B, Schray-Utz B, Busse R. Nitric oxide modulates the expression of monocyte chemoattractant protein 1 in cultured human endothelial cells. Circ Res. 1995;76:980-6.

View Article Google Scholar

20. Tsao PS, Wang B, Buitrago R, Shyy JY, Cooke JP. Nitric oxide regulates monocyte chemotactic protein- 1 . Circulation. 1997;96:934-40.

View Article Google Scholar 
21. De Caterina R Libby P Peng HB Thannickal VJ Rajavashisth TB Gimbrone MA Jr Shin WS Liao JK Nitric oxide decreases cytokine-induced endothelial activation. Nitric oxide selectively reduces endothelial expression of adhesion molecules and proinflammatory cytokines J Clin Invest 199596160 8185173 10.1172/JCI118074

22. Tsao PS, Buitrago R, Chan JR, Cooke JP. Fluid flow inhibits endothelial adhesiveness. Nitric oxide and transcriptional regulation of VCAM-1. Circulation. 1996;94:1682-9.

View Article Google Scholar

23. Resnick N, Gimbrone MAJ. Hemodynamic forces are complex regulators of endothelial gene expression. FASEB J. 1995;9:874-882.

View Article Google Scholar

24. Mees B, Wagner S, Ninci E, Tribulova S, Martin S, van Haperen R, Kostin S, Heil M, de Crom R, Schaper W. Endothelial nitric oxide synthase activity is essential for vasodilation during blood flow recovery but not for arteriogenesis. Arterioscler Thromb Vasc Biol. 2007;27:1926-33.

View Article Google Scholar

25. Khmelewski E, Becker A, Meinertz T, Ito WD. Tissue resident cells play a dominant role in arteriogenesis and concomitant macrophage accumulation. Circ Res. 2004;95:E56-64.

View Article Google Scholar

26. Polfliet MM, Fabriek BO, Daniels WP, Dijkstra CD, van den Berg TK. The rat macrophage scavenger receptor CD163: expression, regulation and role in inflammatory mediator production. Immunobiology. 2006;211:419-25.

View Article Google Scholar

27. Jacobi J, Tam BY, Wu G, Hoffman J, Cooke JP, Kuo CJ. Adenoviral gene transfer with soluble vascular endothelial growth factor receptors impairs angiogenesis and perfusion in a murine model of hindlimb ischemia. Circulation. 2004;110:2424-9.

View Article Google Scholar

28. Scholz D, W Ito, Fleming I, Deindl E, Sauer A, Wiesnet M, Busse R, Schaper J, Schaper W. Ultrastructure and molecular histology of rabbit hind-limb collateral artery growth (arteriogenesis). Virchows Archiv-An International Journal of Pathology. 2000;436:257-270.

View Article Google Scholar

29. Zengin E, Chalajour F, Gehling UM, Ito WD, Treede H, Lauke H, Weil J, Reichenspurner H, Kilic N, Ergun S. Vascular wall resident progenitor cells: a source for postnatal vasculogenesis. Development. 2006;133:1543-51.

View Article Google Scholar

30. Distasi MR Case J Ziegler MA Dinauer MC Yoder MC Haneline LS Dalsing MC Miller SJ Labarrere CA Murphy MP Ingram DA Unthank JL Suppressed hindlimb perfusion in Rac2-/- and Nox2-/- mice does not result from impaired collateral growth Am J Physiol Heart Circ Physiol 20092963 H877 862660231 10.1152/ajpheart.00772.2008

31. Aicher A, Heeschen C, Mildner-Rihm C, Urbich C, Ihling C, Technau-Ihling K, Zeiher AM, Dimmeler S. Essential role of endothelial nitric oxide synthase for mobilization of stem and progenitor cells. Nat Med. 2003;9:1370-6.

View Article Google Scholar

32. Rentrop KP, Feit F, Sherman W, Thornton JC. Serial angiographic assessment of coronary-artery obstruction and collateral flow in acute myocardial-infarction - report from the 2nd mount- sinai-new-yorkuniversity reperfusion trial. Circulation. 1989;80:1166-1175.

View Article Google Scholar

33. Stabile E, Burnett MS, Watkins C, Kinnaird T, Bachis A, la Sala A, Miller JM, Shou M, Epstein SE, Fuchs S. Impaired arteriogenic response to acute hindlimb ischemia in CD4-knockout mice. Circulation. 2003;108:205-10.

View Article Google Scholar 